\title{
STRONTIUM ISOTOPIC ANOMALIES IN THE ALLENDE METEORITE
}

\author{
D. A. Papanastassiou and G. J. Wasserburg \\ The Lunatic Asylum, Div. of Geological and Planetary Sciences, California Institute of Technology, Pasadena, CA 91125
}

Abstract. We report $\mathrm{Sr}$ isotope anomalies in two $\mathrm{Ca}$-Al-rich inclusions (EK1-4-1 and C1) of the Allende meteorite which also contain anomalies in $\mathrm{O}, \mathrm{Mg}, \mathrm{Ca}, \mathrm{Ba}, \mathrm{Nd}$ and $\mathrm{Sm}$. The Sr effects correspond to ${ }^{84} \mathrm{Sr}$ or ${ }^{88} \mathrm{Sr}$ deficits of $3.2 \%$ and $0.8 \%$ or to ${ }^{86} \mathrm{Sr}$ excesses of $1.6 \%$ and $0.4 \%$. Although it cannot be ascertained in which isotope the anomalies reside, arguments based on the ${ }^{87} \mathrm{Sr}$ abundance indicate that the anomalies may reside in ${ }^{84} \mathrm{Sr}$ and ${ }^{86} \mathrm{Sr}$. The data indicate deficits in the p-process component $\left({ }^{84} \mathrm{Sr}\right)$ up to $3.2 \%$ or in the r-process component in $\mathrm{Sr}\left({ }^{88} \mathrm{Sr}\right)$ of up to $32 \%$ and are not easily reconcilable with effects in $\mathrm{Ba}$ and $\mathrm{Nd}$, which indicate excess $\mathrm{r}$, and in $\mathrm{Sm}$, which indicate excess $\mathrm{r}$ and $\mathrm{p}$ components. The existence of positive and negative anomalies for many elements requires an isotopically heterogeneous solar system at the time of formation of these inclusions. The use of ${ }^{87} \mathrm{Sr} /{ }^{86} \mathrm{Sr}$ as a chronometer in the early solar system requires reevaluation, although the anomalies found in $\mathrm{Sr}$ thus far do not show the presence of any obvious artifacts in ${ }^{87} \mathrm{Sr} /{ }^{86} \mathrm{Sr}$.

\section{Introduction}

We report $\mathrm{Sr}$ isotopic anomalies in two $\mathrm{Ca}-\mathrm{Al}$-rich inclusions from the Allende meteorite. These anomalies result from shifts in isotopic abundance which cannot be attributed to the decay of ${ }^{87} \mathrm{Rb}$. Measurements were undertaken after the discovery of isotopic anomalies for $\mathrm{Ca}, \mathrm{Ba}$ and $\mathrm{Nd}$ [Lee, Papanastassiou and Wasserburg, 1978, referred to as LPW; McCulloch and Wasserburg, 1978a]. The first interest in one of these inclusions (C1) was based on the observation of highly fractionated $\mathrm{Mg}$ isotope abundances $(\sim 30 \%$ per mass unit difference) and of a ${ }^{26} \mathrm{Mg}$ deficit $\left(\delta^{26} \mathrm{Mg}=-1.8 \%\right)$ [Lee and Papanastassiou, 1974; LPW, 1976]. This sample was also found to contain oxygen with an isotope composition distinctly off the Extraordinary ${ }^{16} \mathrm{O}$ - Normal $\mathrm{O}$ mixing line [Clayton, Onuma, Grossman and Mayeda, 1977]. The importance and the correlation of these doubly anomalous $\mathrm{Mg}$ and $\mathrm{O}$ isotopic patterns became manifest after the identification of a similar pattern in a second Ca-Al-rich inclusion, EK1-4-1 [cf. Clayton and Mayeda, 1977, and Wasserburg, Lee and Papanastassiou, 1977]. These anomalies have been labelled FUN for Fractionation and Unknown Nuclear effects.

Prior to the discovery of isotopic heterogeneities in the major element oxygen [Clayton, Grossman and Mayeda, 1973], the measurement of Sr isotopes in Allende inclusions had addressed the identification of differences in initial ${ }^{87} \mathrm{Sr} /{ }^{86} \mathrm{Sr}$ and their possible interpretation as due to the decay of ${ }^{87} \mathrm{Rb}$ in the early solar system. Differences in initial ${ }^{87} \mathrm{Sr} /{ }^{86} \mathrm{Sr}$ provide a chronometer for the condensation of solar system materials with a resolution of $\sim 10^{6}$ years [Papanastassiou and Wasserburg, 1969; Gray, Papanastassiou and Wasserburg (GPW), 1973a,b]. The study by GPW [1973a,b] established the presence of measured ${ }^{87} \mathrm{Sr} /{ }^{86} \mathrm{Sr}$ in an Allende inclusion which was lower than the BABI value by $0.3 \%$ and demonstrated that some inclusions represented the oldest known materials in the solar system. Measurements of ${ }^{84} \mathrm{Sr}$ by GPW [1973b] on three inclusions showed normal ${ }^{84} \mathrm{Sr} /{ }^{88} \mathrm{Sr}$. Cameron [personal communication and 1973] proposed that the low initial ${ }^{87} \mathrm{Sr} /{ }^{86} \mathrm{Sr}$ in Angra dos Reis and in Allende could be due to an ${ }^{88} \mathrm{Sr}$ excess in these samples. For the data representation used, an excess of ${ }^{88} \mathrm{Sr}$ would appear as a deficiency in ${ }^{87} \mathrm{Sr}$. Cameron argued that the observed differences would correspond to a relative excess in ${ }^{88} \mathrm{Sr}$ of up to $0.6 \%$ due to the presence of a $\sim 6 \%$ excess r-process component. As pointed out by GPW [1973b], if the low ${ }^{87} \mathrm{Sr} /{ }^{86} \mathrm{Sr}$ were an artifact, similar artifacts would be obtained for ${ }^{84} \mathrm{Sr} /{ }^{8} 8 \mathrm{Sr}$ corresponding up to a $0.6 \%$ excess in ${ }^{84} \mathrm{Sr}$.

Copyright 1978 by the American Geophysical Union.
Such small effects in ${ }^{84} \mathrm{Sr}$ would have been hard to resolve and were not found by GPW [1973b]. In this work we report Sr isotopic anomalies, discuss their correlation with other FUN anomalies, and review the implications of the anomalies for the use of ${ }^{87} \mathrm{Sr} /{ }^{86} \mathrm{Sr}$ as a chronometer. The $\mathrm{Sr}$ results were presented by Papanastassiou, Huneke, Esat and Wasserburg [1978].

\section{Results}

Measurement of the rare isotope ${ }^{84} \mathrm{Sr}$ requires considerable care as it is sensitive to a) possible non-linearities in the data collection system, b) non-linearities in the response of the electrometer feedback resistor ("polarization effects") during and subsequent to the ${ }^{88} \mathrm{Sr}$ measurement, and c) possible mass interferences. To monitor these effects, we obtained data by:

A) Collection of sequential cycles of masses $88,87,86,84$, 88 , using the $10^{10} \Omega$ resistor while the ${ }^{88} \mathrm{Sr}$ beam intensity was kept in the range 4-6 $\times 10^{-11} \mathrm{~A}$. Ratios were corrected for mass fractionation by normalization of ${ }^{86} \mathrm{Sr} /{ }^{8} 8 \mathrm{Sr}$ to 0.1194 .

B) Collection of sequential cycles of masses $87,86,84,87$, using the $10^{11} \Omega$ resistor with ${ }^{86} \mathrm{Sr} \sim 0.5-0.7 \times 10^{-11} \mathrm{~A}$ as in case-A. The ratios were corrected for mass fractionation by normalization of ${ }^{87} \mathrm{Sr} /{ }^{86} \mathrm{Sr}$ to the mean ${ }^{87} \mathrm{Sr} /{ }^{86} \mathrm{Sr}$ from $\mathrm{A}$.

C) Collection of sequential cycles of masses $88,87,86,84$, 88 , using the $10^{11} \Omega$ resistor with ${ }^{88} \mathrm{Sr}$ in the range of $4-5 \times 10^{-11} \mathrm{~A}$. The ratios were corrected for mass fractionation by normalization of the ${ }^{86} \mathrm{Sr} /{ }^{88} \mathrm{Sr}$ to 0.1194 .

Data collection for procedure $\mathbf{A}$ is most sensitive to possible non-linearities and to unfavorable signal to noise ratios $\left({ }^{8} \mathrm{Sr} \sim 3 \times 10^{-3} \mathrm{~V}\right)$. Procedure $\mathrm{B}$ is subject to possible bias by the propagation of differences in 8 8-86 $\mathrm{Sr}$ measurements on the two resistors. Procedure $C$ is most sensitive to polarization effects during measurement of ${ }^{88} \mathrm{Sr}$, but has the most favorable signal to noise ratio for all isotopes. Data were obtained using all procedures A-C; however, for any individual run it was not always possible to obtain data using all procedures.

During the course of the experiments, the Lunatic I mass spectrometer suffered a serious breakdown of the reference voltage supply within the digital voltmeter (DVM). The instrument was repaired by using old spare components. The tables give the sequential run number; the DVM breakdown occurred between runs 802 and 803 . Extensive calibrations of the Lunatic I using seawater Sr before and after breakdown indicate no resolvable shift for the ${ }^{84} \mathrm{Sr} /{ }^{88} \mathrm{Sr}$ ratio (Table 2). For ${ }^{87} \mathrm{Sr} /{ }^{86} \mathrm{Sr}$ there is an indication for a shift after the breakdown of 0.00005 towards lower values for the $10^{10} \Omega$ data for which extensive documentation exists prior to the breakdown. This shift is at the limit of resolution for an individual $\mathrm{Sr}$ run and is not important for ${ }^{87} \mathrm{Sr} /{ }^{86} \mathrm{Sr}$ for the purposes of this work. For data collection procedure $\mathrm{B}$, this possible shift in ${ }^{87} \mathrm{Sr} /{ }^{86} \mathrm{Sr}$ would reduce the ${ }^{84} \mathrm{Sr} /{ }^{88} \mathrm{Sr}$ by $0.1 \%$. For the work described here, samples were processed totally in new teflon beakers and no tracers were added to solutions used for isotopic composition measurements. Samples were eluted through ion exchange columns which are also used for samples spiked with ${ }^{84} \mathrm{Sr}$. However, the column blanks are negligible. In any case, the observed effects correspond to deficiencies in ${ }^{84} \mathrm{Sr}$ and cannot be attributed to the use of the ${ }^{84} \mathrm{Sr}$ tracer.

Enriched Standards. To demonstrate our resolution, we prepared solutions enriched in ${ }^{84} \mathrm{Sr}$ using a seawater $\mathrm{Sr}$ standard and $a^{84} \mathrm{Sr}$ solution of known concentration and isotopic composition. Table 1 shows the results for the $0.9 \%$, $1.9 \%$, and $3.8 \%$ standards. For the $10^{11} \Omega$ data we see a clear resolution of the $1.9 \%$ and $3.8 \%$ effects; the $10^{10} \Omega$ data on 
Table 1. ${ }^{84} \mathrm{Sr}$ Enriched Standards

\begin{tabular}{|c|c|c|c|c|c|c|}
\hline \multirow{2}{*}{$\begin{array}{l}\text { Standard }{ }^{\mathrm{a}} \\
\delta 84(\% 0)\end{array}$} & \multirow[t]{2}{*}{ Run } & \multicolumn{3}{|c|}{$884(\% 0)^{b}$} & \multicolumn{2}{|c|}{${ }^{87} \mathrm{Sr} / /^{86} \mathrm{Sr}$} \\
\hline & & $10^{11} \Omega^{\mathrm{c}}$ & & $10^{10} \Omega^{8}$ & $10^{11} \Omega^{c}$ & $10^{10} \Omega^{\circ}$ \\
\hline & $\begin{array}{l}812 \\
836 \\
841\end{array}$ & $\begin{array}{c}-\overline{-} \\
+0.8 \pm 0.2 \\
+0.7 \pm 0.3\end{array}$ & & & $\begin{array}{c}-\overline{0} \\
0.70903 \pm 3 \\
0.70902 \pm 3\end{array}$ & $\begin{array}{c}0.70905 \pm 12 \\
0.70903 \pm 4 \\
\end{array}$ \\
\hline 1.9 & & $+\overline{1.6 \pm 0.3}$ & $\begin{array}{c}+1.9 \pm 0.4 \\
--\end{array}$ & $\begin{array}{c}+1.2 \pm 0.5 \\
--\end{array}$ & $0 . \overline{-}-\overline{0908 \pm 6}$ & ${ }^{0.70902 \pm 4}$ \\
\hline & $\begin{array}{l}832 \\
839\end{array}$ & $\begin{array}{r}+3.4 \pm 0.3 \\
+3.5 \pm 0.2\end{array}$ & $+\overline{3.7 \pm 0.3}$ & - & $\begin{array}{l}0.70909 \pm 4 \\
0.70910 \pm 3\end{array}$ & $0 . \overline{-}$ \\
\hline
\end{tabular}

${ }^{9} 8^{84} \mathrm{Sr}$ (in per mil) for standard determined by gravimetry. ${ }^{b} \delta^{84} \mathrm{Sr}$ (in per mil) measured relative to the normal value ${ }^{84} \mathrm{Sr} /{ }^{83} \mathrm{Sr}=0.006745$. ${ }^{c} \mathrm{All}$ isotopes measured using the $10^{11} \Omega$ resistor; data normalized to ${ }^{86} \mathrm{Sr} /{ }^{88} \mathrm{Sr}=0.1194$. ${ }^{\mathrm{d}}$ Isotopes $87,86,84$ measured on the $10^{11} \Omega$ resistor. ${ }^{D}$ All isotopes measured on $10^{10} \Omega$ resistor.

the $1.9 \%$ standard, al though less precise, also permit resolution of this effect. Two high quality analyses for the $0.9 \%$ standard demonstrate the unambiguous resolution of effects of this size. The uncertainties in ${ }^{84} \mathrm{Sr} /{ }^{88} \mathrm{Sr}$ are $0.2-0.4 \%(2 \sigma)$ for good quality runs using the $10^{11} \Omega$ resistor. We show in Fig. 1 the data on the enriched standards. From these data we conclude that $2 \%$ effects are clearly resolvable and $1 \% 0$ effects are resolved for high quality analyses.

Normal ${ }^{84} \mathrm{Sr} /{ }^{8} \mathrm{Sr}$. We analyzed seawater, bulk Allende and Murchison samples, pyroxene from Angra dos Reis, and lunar anorthosite 60025 . Using the $10^{11} \Omega$ data obtained on Lunatic $I$, we determine a grand mean ${ }^{84} \mathrm{Sr} /{ }^{88} \mathrm{Sr}=0.0067450 \pm 0.0000007$ for normal $\mathrm{Sr}$. This is $0.4 \%$ lower than the previous value in use in this laboratory [GPW, 1973b].$^{84} \mathrm{Sr}$ data on $10^{10} \Omega$ are $0.2 \%$ lower and are consistent within their larger uncertainties with the $10^{11} \Omega$ data. In addition, the $10^{11} \Omega$ data obtained on Lunatic III are in excellent agreement with the Lunatic I data; the $10^{10} \Omega$ data are in agreement within their significantly larger uncertainties. Since the ${ }^{84} \mathrm{Sr} /{ }^{88} \mathrm{Sr}$ data obtained using the $10^{11} \Omega$ resistor are much more precise than the $10^{10} \Omega$ data, we will use the $10^{11} \Omega^{84} \mathrm{Sr} / 88 \mathrm{Sr}$ data exclusively for the rest of this paper. The ${ }^{87} \mathrm{Sr} /{ }^{86} \mathrm{Sr}$ show excellent agreement between the Lunatic I and III spectrometers. There is excellent agreement for ${ }^{87} \mathrm{Sr} /{ }^{86} \mathrm{Sr}$ between data obtained on $10^{11} \Omega$ and $10^{10} \Omega$, indicating negligible nonlinearities and feedback resistor polarization effects for the beam intensities used.

FUN Samples. For EK1-4-1 we analyzed pyroxene and melilite separates and a scoop of the crushed sample consisting dominantly of pyroxene. The data yield identical ${ }^{84} \mathrm{Sr} /{ }^{88} \mathrm{Sr}$ in all samples corresponding to $\delta^{84} \mathrm{Sr}=-3.2 \pm 0.2 \%$. The effects in the pyroxene and the melilite are indistinguishable (note the lower precision of the melilite data) although the $\mathrm{Sr}$ concentrations differ by a factor of five. To confirm that the ${ }^{84} \mathrm{Sr} /{ }^{88} \mathrm{Sr}$ in the EK 1-4-1 pyroxene sample was indeed due to a depletion of ${ }^{84} \mathrm{Sr}$, we doped the sample by adding sufficient ${ }^{84} \mathrm{Sr}$ to increase this isotope by $4.0 \%$. Analyses of the doped sample on both the Lunatic I and III are consistent with the analysis of the original sample. Analyses on both the Lunatic I and III for EK1-4-1 (Pyx) yield consistent results. These data establish the presence in EK 1-4-1 of nuclear anomalies corresponding to a deficiency in ${ }^{84} \mathrm{Sr}$ of $3.2 \%$. For $\mathrm{Cl}$ we analyzed samples of the total inclusion and of two pyroxene separates. The data from the four analyses yield $\delta^{84} \mathrm{Sr}=-0.8 \pm 0.2 \%$, corresponding to a clearly resolvable deficit in ${ }^{84} \mathrm{Sr}$. We have also analyzed $\mathrm{Sr}$ in the anorthite from inclusion WA, which showed $\delta^{26} \mathrm{Mg} \approx 100 \%$ [LPW, 1977]. The small sample size results in an imprecise analysis from which we can exclude the presence of large effects. We show in Table 2 a new analysis of melilite crystals from Allende inclusion $\mathrm{D} 7$ which defines the most primitive ${ }^{87} \mathrm{Sr} /{ }^{86} \mathrm{Sr}$ value of ALL [GPW, 1973a,b]. This sample yields normal ${ }^{84} \mathrm{Sr}$ isotopic composition. Analysis of lunar anorthosite 60025, which yields the lowest measured ${ }^{87} \mathrm{Sr} /{ }^{86} \mathrm{Sr}$ on the moon, yields normal ${ }^{84} \mathrm{Sr} /{ }^{88} \mathrm{Sr}$.

\section{Discussion}

All data on ${ }^{84} \mathrm{Sr}$ in terrestrial and extraterrestrial samples are given in Table 2. With the exception of the two FUN samples, there are no variations in the ${ }^{84} \mathrm{Sr}$ abundance. We include "bulk" samples of Allende, Murchison, Angra dos Reis, lunar anorthosite 60025, and seawater. Ca-Al-rich inclusions D6 and D7 and a pyroxene chondrule from Allende are also normal. A plagioclase (WA) which contains $100 \%$ excess of ${ }^{26} \mathrm{Mg}$ due to ${ }^{26} \mathrm{Al}$ decay [LPW, 1977] shows normal ${ }^{84} \mathrm{Sr}$ abundance. These data, while limited, indicate that variations in ${ }^{84} \mathrm{Sr}$ are in general not large or common. There is no correlation of ${ }^{84} \mathrm{Sr}$ variations with excess ${ }^{26} \mathrm{Mg}$. Further, there is no apparent effect in ${ }^{84} \mathrm{Sr}$ which is correlated with the degree of primitiveness of the $\mathrm{Sr}$ as inferred from ${ }^{87} \mathrm{Sr} /{ }^{86} \mathrm{Sr}$. By contrast, the two FUN-type inclusions contain significant ${ }^{84} \mathrm{Sr}$ anomalies which represent deficiencies of $3.2 \%$ and $0.8 \%$ in inclusions EK 1-4-1 and C1, respectively. These anomalies are uniform for different mineral phases within each inclusion. This is in accord with the observed isotopic anomalies in $\mathrm{Mg}$, $\mathrm{Ca}, \mathrm{Ba}, \mathrm{Nd}$ and $\mathrm{Sm}$ in the same samples [Wasserburg et al., 1977; LPW, 1978; McCulloch and Wasserburg, 1978a,b]. The ${ }^{84} \mathrm{Sr}$ effects do not correlate with the degree of fractionation observed for $\mathrm{Mg}$ in the FUN inclusions as the $\mathrm{Mg}$ in EK 1-4-1 is less fractionated than in $\mathrm{Cl}$.

We now address the problem of whether the observed isotopic anomalies in $\mathrm{Sr}$ can be assigned to a specific isotope. The measured ${ }^{86} \mathrm{Sr} /{ }^{88} \mathrm{Sr}$ ratios (without normalization) in the FUN inclusions fall in the typical range of values observed for all other samples. Relative to ${ }^{86} \mathrm{Sr} /{ }^{88} \mathrm{Sr}=0.1194$, the measured ${ }^{86} \mathrm{Sr} /{ }^{88} \mathrm{Sr}$ are higher by up to 4 to $6 \%$ at the beginning of data acquisition, decline in a regular manner during the run and reach -4 to $-6 \%$ toward the end of data acquisition due to mass dependent fractionation. We believe that a uniform offset in the observed range in ${ }^{86} \mathrm{Sr} /{ }^{88} \mathrm{Sr}$ during a run by more than $4 \%$ would provide definite evidence of ${ }^{86} \mathrm{Sr} /{ }^{8} 8 \mathrm{Sr}$ values distinct from normal. We conclude that ${ }^{86} \mathrm{Sr} /{ }^{88} \mathrm{Sr}$ differences between all samples, including the FUN inclusions, are less than $4 \%$. Similarly, differences in raw ${ }^{84} \mathrm{Sr} /{ }^{88} \mathrm{Sr}$ are less than $8 \%$. The non-linear isotopic effects in $\mathrm{Sr}$, although adequately resolved, are comparable with the range of instrumental fractionation effects and it is thus not possible to establish in which specific $\mathrm{Sr}$ isotope the anomaly resides. We have so far represented the data normalizing the results to ${ }^{86} \mathrm{Sr} /{ }^{88} \mathrm{Sr}$. If we consider alternate representations in which different pairs

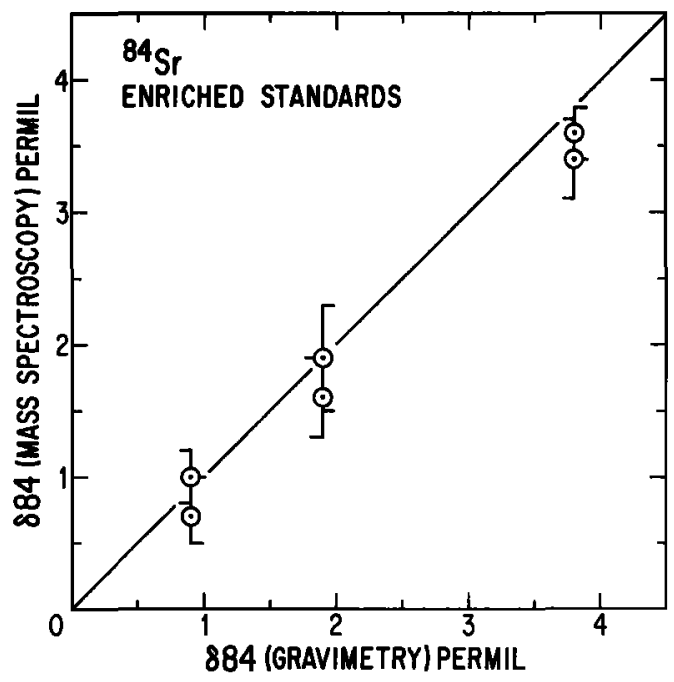

Fig. 1. ${ }^{84} \mathrm{Sr}$ enriched standards. The line shown has unit slope and passes through the origin. Effects in ${ }^{84} \mathrm{Sr}$ of $1 \%$ and larger are clearly resolved. 
of the isotopes, which are not affected by long-lived radioactive decay, are assumed to have normal abundance, we obtain $\delta^{84} \mathrm{Sr}\left({ }^{86} \mathrm{Sr},{ }^{88} \mathrm{Sr}\right)=\delta^{88} \mathrm{Sr}\left({ }^{84} \mathrm{Sr},{ }^{86} \mathrm{Sr}\right)=-2 \delta^{86} \mathrm{Sr}\left({ }^{84} \mathrm{Sr},{ }^{88} \mathrm{Sr}\right)$, where the variation of the third isotope is given relative to the pair shown in parentheses and used for normalization. For example, the isotopic anomaly in EK1-4-1 can be due to a $3.2 \%$ deficit in ${ }^{84} \mathrm{Sr}$ or ${ }^{88} \mathrm{Sr}$ or a $1.6 \%$ excess in ${ }^{86} \mathrm{Sr}$. For the relative number of nuclei required to produce the observed anomalies in the different representations, we have ${ }^{84} \mathrm{Sr}:{ }^{86} \mathrm{Sr}:{ }^{8} \mathrm{Sr}=(-1):(+9):(-150)$.

We now consider the implications of two types of models to produce the $\mathrm{Sr}$ isotopic anomalies: a) modification of solar system isotopic abundances to produce the observed effects, and $b$ ) addition of exotic materials to the solar system. In case (a) we consider the solar system abundances as well defined and being only slightly modified possibly on a local scale (in a zone of a star or possibly in the solar system itself). For case (a) we may consider the possibility that the $\mathrm{Sr}$ effects are produced by exposure of material of solar abundance to a relatively weak neutron fluence. The $\mathrm{Sr}$ isotopes 86,87 , and 88 are on the s-process path; ${ }^{87} \mathrm{Sr}$ and ${ }^{88} \mathrm{Sr}$ have small r-process components, while ${ }^{86} \mathrm{Sr}$ is an s-only isotope. If the $\mathrm{Rb}$ in the solar system were mostly produced by the $s$ process, then further processing of these s-process materials with a relatively weak neutron fluence would result in basically no change in the ${ }^{86-88} \mathrm{Sr}$ abundances, while ${ }^{84} \mathrm{Sr}$ would be destroyed; this behavior would be consistent with the observed $\mathrm{Sr}$ effects. For solar abundances, however, ${ }^{85} \mathrm{Rb}$ and ${ }^{87} \mathrm{Rb}$ are significantly enhanced by $r$-process contributions and by the decay of the s-process equilibrium abundance of ${ }^{85} \mathbf{K r}\left(\tau_{1 / 2}=10.7 \mathrm{yr}\right)$. Exposure of materials with solar system abundances to a neutron fluence would therefore result in destruction of ${ }^{84} \mathrm{Sr}$ and also in production of excess ${ }^{86} \mathrm{Sr}$ relative to ${ }^{87} \mathrm{Sr}$ and ${ }^{88} \mathrm{Sr}$. This would also be consistent with the $\mathrm{Sr}$ data and require a factor of eight lower neutron fluence than in the case where only ${ }^{84} \mathrm{Sr}$ is destroyed. Insofar as the cross sections behave as $1 / v$, the effects described will not be sensitive to the temperature of the neutron bath. If we consider irradiation of materials highly depleted in $\mathrm{Rb}$, we obtain comparable depletions in ${ }^{84} \mathrm{Sr}$ and ${ }^{86} \mathrm{Sr}$, which is inconsistent with the observed $\mathrm{Sr}$ effects. The neutron fluence required to produce the $\mathrm{Sr}$ isotopic anomalies from solar system materials is $\sim 10^{22} \mathrm{n} / \mathrm{cm}^{2}$ and would seriously affect other nuclides. We would expect a large depletion of ${ }^{149} \mathrm{Sm}$, which has a neutron cross-section at $30 \mathrm{keV}$ an order of magnitude larger than the neutron capture cross-sections for ${ }^{84} \mathrm{Sr},{ }^{86} \mathrm{Sr}$ and ${ }^{87} \mathrm{Sr}$. These depletions are not observed [Lugmair, Marti and Scheinin, 1978; McCulloch, Wasserburg and Papanastassiou, 1978; McCulloch and Wasserburg, 1978b].

We now consider the possible addition of exotic materials to the solar system. From canonical nucleosynthesis [Burbidge, Burbidge, Fowler and Hoyle, 1957; Seeger, Fowler and Clayton, 1965$]^{84} \mathrm{Sr}$ is a p-process nuclide, ${ }^{86} \mathrm{Sr}$ is s-only, ${ }^{87} \mathrm{Sr}$ is mainly $s$ but with contributions from the decay of ${ }^{87} \mathrm{Rb}$, and ${ }^{88} \mathrm{Sr}$ is produced $\sim 90 \%$ by s- and $10 \%$ by r-process. The $\mathrm{Sr}$ effects in EK1-4-1 and $\mathrm{Cl}$ (respectively) are compatible with the following alternatives: a) relative deficits in the p-process component of $3.2 \%$ and $0.8 \%$ or equivalent excesses in all the s-process nuclides; b) relative deficits in ${ }^{88} \mathrm{Sr}$ of $3.2 \%$ and $0.8 \%$ with no effects in ${ }^{84} \mathrm{Sr}$ or ${ }^{86} \mathrm{Sr}$. This would correspond to $32 \%$ and $8 \%$ deficits in the r-component for $\mathrm{Sr}$; c) relative excesses in ${ }^{86} \mathrm{Sr}$ of $1.6 \%$ and $0.4 \%$ and no effects in ${ }^{84} \mathrm{Sr}$ or ${ }^{88} \mathrm{Sr}$. This case would require a separate and distinctive s-process addition not operating at equilibrium.

The identification of the processes responsible for the isotopic anomalies must rely on correlated measurements on the same samples over a large range in $\mathrm{Z}$. Measurements of $\mathrm{Ba}$ and $\mathrm{Sm}$ in EK 1-4-1 and $\mathrm{Cl}$ provide the chance to look at the effects in p-process isotopes ${ }^{130} \mathrm{Ba},{ }^{132} \mathrm{Ba}$ and ${ }^{144} \mathrm{Sm}$. No p-process effects have been resolved in $\mathrm{Ba}[\mathrm{McCulloch}$ and Wasserburg, 1978a] in these samples. Excesses in ${ }^{144} \mathrm{Sm}$ have
Table 2. Sr Isotopic Abundance

\begin{tabular}{|c|c|c|c|c|c|c|}
\hline \multirow{2}{*}{ Sample ${ }^{\mathbf{i}}$} & \multirow{2}{*}{ Run } & \multicolumn{3}{|c|}{$\delta 84(\%)^{\mathrm{a}}$} & \multicolumn{2}{|c|}{${ }^{87} \mathrm{Sr} /{ }^{86} \mathrm{Sr}^{\mathrm{a}, \mathrm{h}}$} \\
\hline & & $10^{11} \Omega^{\mathrm{b}}$ & $10^{11} \Omega^{\mathrm{c}}$ & $10^{10} \Omega^{\mathrm{d}}$ & $10^{11} \Omega^{\mathrm{b}}$ & $10^{10} \Omega^{\mathrm{d}}$ \\
\hline \multicolumn{7}{|c|}{ Allende EK1-4-1 (FUN) } \\
\hline \multirow[t]{3}{*}{ Pyx } & 818 & $-3.4 \pm 0.4$ & -- & $-4.1 \pm 0.8$ & $0.69969 \pm 9$ & $0.69973 \pm 10$ \\
\hline & 834 & $-3.7 \pm 0.3$ & - & $-4.7 \pm 0.8$ & $0.69973 \pm 4$ & $0.69979 \pm 8$ \\
\hline & $3^{e}$ & $-3.2 \pm 0.3$ & -- & $-4.0 \pm 0.7$ & $0.69968 \pm 3$ & $0.69981 \pm 6$ \\
\hline \multirow[t]{2}{*}{ Doped $^{f}$} & 825 & $+0.5 \pm 0.3$ & $+0.7 \pm 0.3$ & $+0.5 \pm 0.7$ & $0.69969 \pm 4$ & $0.69971 \pm 6$ \\
\hline & $4^{e}$ & $+0.4 \pm 0.3$ & -- & -- & $0.69968 \pm 4$ & (1) \\
\hline Melilite & 803 & -- & $-2.6 \pm 0.8$ & $-3.0 \pm 0.8$ & -- & $0.70160 \pm 9$ \\
\hline \multirow[t]{2}{*}{ Scoop } & 824 & $-2.9 \pm 0.3$ & -- & $-3.2 \pm 2.2$ & $0.70099 \pm 6$ & $0.70112 \pm 32$ \\
\hline & 801 & - & $-3.1 \pm 0.6$ & $-3.3 \pm 0.7$ & -- & $0.70105 \pm 8$ \\
\hline \multicolumn{7}{|c|}{ Allende $\mathrm{C} 1$ (FUN) } \\
\hline Pyx-A & 835 & $-0.9 \pm 0.2$ & -- & -- & $0.70127 \pm 3$ & $0.70123 \pm 8$ \\
\hline Pyx-B & 837 & $-0.9 \pm 0.2$ & $-0.8 \pm 0.3$ & -- & $0.70099 \pm 4$ & $0.70093 \pm 4$ \\
\hline Total S1 & 813 & -- & $-0.7 \pm 0.3$ & - & -- & $0.70392 \pm 9$ \\
\hline \multirow[t]{2}{*}{ Total S2 } & 814 & -- & $-0.5 \pm 0.3$ & $-0.9 \pm 0.8$ & -- & $0.70379 \pm 8$ \\
\hline & 787 & -- & -- & $-2.0 \pm 0.8$ & -- & $0.70381 \pm 9$ \\
\hline
\end{tabular}

Allende WA

Anorthite 772 + +0

\begin{tabular}{llccccl} 
D7 & 838 & $-0.4 \pm 0.2$ & $-0.1 \pm 0.4$ & -- & $0.69886 \pm 3$ & $0.69884 \pm 5$ \\
D7 $^{\mathrm{g}}$ & 515 & -- & -- & $+0.9 \pm 0.6$ & -- & $0.69877 \pm 4$ \\
D6 $^{\mathrm{g}}$ & 517 & -- & -- & $-0.1 \pm 0.3$ & -- & $0.69925 \pm 4$ \\
E1 $^{\mathrm{g}}$ (Pyx) & 520 & -- & -- & $0.0 \pm 0.3$ & -- & $0.77479 \pm 11$ \\
All-bulk & 811 & -- & $0.0 \pm 0.5$ & $-0.1 \pm 0.6$ & -- & $0.71271 \pm 4$ \\
Mur-bulk & 817 & $+0.2 \pm 0.3$ & $-0.1 \pm 0.4$ & $-0.5 \pm 1.0$ & $0.73071 \pm 7$ & $0.73077 \pm 11$ \\
Angra dos & 823 & $+0.0 \pm 0.3$ & $0.0 \pm 0.5$ & $-0.6 \pm 0.6$ & $0.69886 \pm 3$ & $0.69883 \pm 4$ \\
Reis & 802 & -- & $-0.2 \pm 0.5$ & $0.0 \pm 0.4$ & -- & $0.69890 \pm 4$ \\
60025 & 840 & $-0.1 \pm 0.2$ & -- & -- & $0.69895 \pm 3$ & -- \\
Seawater & 833 & $0.0 \pm 0.2$ & -- & $0.0 \pm 0.6$ & $0.70904 \pm 3$ & $0.70911 \pm 4$ \\
Sr & 827 & $+0.3 \pm 0.3$ & -- & -- & $0.70899 \pm 6$ & -- \\
& 828 & $-0.2 \pm 0.2$ & - & -- & $0.70905 \pm 5$ & -- \\
& 816 & $-0.2 \pm 0.2$ & $-0.2 \pm 0.4$ & $-0.2 \pm 0.7$ & $0.70905 \pm 3$ & $0.70907 \pm 5$ \\
& 807 & -- & $+0.1 \pm 0.3$ & $-0.4 \pm 0.6$ & -- & $0.70902 \pm 3$ \\
& 805 & -- & $+0.3 \pm 0.4$ & $-0.5 \pm 0.5$ & -- & $0.70903 \pm 4$ \\
& 800 & -- & -- & $+0.5 \pm 0.8$ & -- & $0.70912 \pm 5$ \\
& 798 & -- & -- & -- & -- & $0.70907 \pm 4$ \\
& 796 & -- & -- & -- & -- & $0.70904 \pm 4$ \\
& 769 & -- & -- & $+0.3 \pm 0.5$ & -- & $0.70909 \pm 4$ \\
& $2^{\mathrm{e}}$ & $-0.2 \pm 0.2$ & -- & $-0.6 \pm 0.6$ & $0.70906 \pm 4$ & $0.70907 \pm 5$ \\
& $1^{\mathrm{e}}$ & -- & $+0.2 \pm 0.4$ & $-0.7 \pm 0.5$ & -- & $0.70905 \pm 4$ \\
\hline
\end{tabular}

a Normalized for mass fractionation using ${ }^{86} \mathrm{Sr} /{ }^{88} \mathrm{Sr}=0.1194$; entries for ${ }^{84} \mathrm{Sr} /{ }^{88} \mathrm{Sr}$ as per mil deviations from normal ${ }^{84} \mathrm{Sr} /{ }^{88} \mathrm{Sr}=0.006745$. ${ }^{\mathrm{b}}$ All isotopes measured on the $10^{11} \Omega$ resistor. ${ }^{c}$ Isotopes $87,86,84$ measured on the $10^{11} \Omega$ resistor; ${ }^{87} \mathrm{Sr} /{ }^{86} \mathrm{Sr}$ was used for normalization. ${ }^{\mathrm{d}}$ All isotopes measured on the $10^{10} \Omega$ resistor. The ${ }^{84} \mathrm{Sr}$ data on $10^{10} \Omega$ are not sufficiently precise and are not used in the paper. ${ }^{e}$ Lunatic III run. ${ }^{\text {f Sample }}$ doped by the addition of sufficient ${ }^{84} \mathrm{Sr}$ to increase $\delta 84$ in the original sample by $4.0 \%$. ${ }^{\mathrm{g} D a t a}$ from GPW [1973b] ${ }^{\mathrm{h}}$ From the measured values we obtain initial ${ }^{87} \mathrm{Sr} /{ }^{86} \mathrm{Sr}$ for FUN samples (assuming T = 4.5 AE): EK1-4-1, pyroxene 0.69898 , melilite 0.69884 , scoop $0.69900 ; \mathrm{C} 1$, pyroxene-A 0.69893, pyroxene-B 0.69900; BABI $=0.69898 ; \mathrm{ALL}=0.69877$ [cf., GPW, 1973b] ${ }^{\mathrm{i}}$ Abbreviations: Pyx = pyroxene; All = Allende; $M u r=$ Murchison.

been reported for EK 1-4-1 and C1 by McCulloch et al. [1978] and McCulloch and Wasserburg [1978b], and for EK 14-1 by Lugmair et al. [1978]. The correlation of these effects (deficit-p for $\mathrm{Sr}$, null-p effects for Ba, and excess-p for $\mathrm{Sm}$ ) is far from obvious. Recent calculations of production of p-process isotopes by photodisintegration reactions by Woosley and Howard [1978] indicate that production of ${ }^{84} \mathrm{Sr}$ requires relatively higher temperature than $\mathrm{Ba}$ or $\mathrm{Sm} \mathrm{p}$ isotopes, so that decoupling of the production of $\mathrm{Sr}$ and of $\mathrm{Ba}$ and $\mathrm{Sm}$ may be possible; similar decoupling of $\mathrm{Ba}$ and $\mathrm{Sm}$ p-process isotopes is less evident. For elements heavier than $\mathrm{Ca}$, the effects in $\mathrm{Sr}, \mathrm{Ba}$, $\mathrm{Nd}$ and $\mathrm{Sm}$ cannot be attributed to the addition of only $s$ or $r$ or $p$ components. In particular, whereas $\mathrm{Ba}, \mathrm{Nd}$ and $\mathrm{Sm}$ appear to require an excess r-component, the $\mathrm{Sr}$ data require an 
r-component deficit or the anomalies in $\mathrm{Sr}$ are due to processes other than $r$. It is therefore likely that a mixture of specific nucleosynthetic processes, astrophysical production sites, and models for extraction of materials from a star will be required to interpret the observed effects.

The observation of negative isotopic anomalies for $\mathrm{Mg}, \mathrm{Ca}$, $\mathrm{Sr}$ and $\mathrm{Ba}$ and in particular the observation of both positive and negative anomalies for $\mathrm{Ca}$ and $\mathrm{Ba}$ indicate that the isotopic anomalies cannot be considered simply to be the result of addition of an extra-solar component to an isotopically homogeneous solar system with the present "normal" values. Instead, the data strongly indicate that the solar nebula was intrinsically not well mixed or that addition of multiple, extra-solar components is required. The effects may result from processing of average presolar material in different zones of a supernova and injection of this material back into the interstellar medium just before the solar system formed, or possibly that $r, s, p$ type contributions from several sources were preserved in the presolar material. The existence of negative isotopic anomalies may have important implications for the total number of nuclides added to the solar system. If we consider an initial solar-system-wide composition as found in the FUN samples which show negative isotopic effects, then we require the addition of significant materials in order to "fill in" the negative anomalies to obtain the normal solar system isotopic abundances.

We now consider the ${ }^{87} \mathrm{Sr}$ abundance in samples with FUN anomalies. For EK 1-4-1 and C1 it is necessary to correct for the in situ decay of ${ }^{87} \mathrm{Rb}$. Previous studies of Allende have established that the $\mathrm{Rb}-\mathrm{Sr}$ and $\mathrm{U}-\mathrm{Th}-\mathrm{Pb}$ systems have been disturbed at possibly recent times, although the mechanisms are not understood [GPW, 1973b; Tatsumoto, Unruh and Desborough, 1976; Chen and Tilton, 1976]. Since the evidence for disturbed $\mathrm{Rb}-\mathrm{Sr}$ systems is provided in part by samples with highly radiogenic ${ }^{87} \mathrm{Sr} /{ }^{86} \mathrm{Sr}$, it is not possible to attribute all the evidence for disturbances in the $\mathrm{Rb}-\mathrm{Sr}$ system to exotic nucleosynthetic components in ${ }^{86} \mathrm{Sr}$ or ${ }^{88} \mathrm{Sr}$. Such effects would be larger by two orders of magnitude than found in EK 1-4-1 and would have easily been seen on the basis of raw ${ }^{86} \mathrm{Sr} /{ }^{88} \mathrm{Sr}$ measurements. For the purpose of comparing initial ${ }^{87} \mathrm{Sr} /{ }^{86} \mathrm{Sr}$ in the following discussion, we use the ${ }^{87} \mathrm{Sr} /{ }^{86} \mathrm{Sr}$ in the sample after correction for in situ ${ }^{87} \mathrm{Rb}$ decay. If we consider a sample to which exotic $\mathrm{Sr}$ was added such that $\kappa, \lambda, \mu, \nu$ are the fractional amounts of ${ }^{84-88} \mathrm{Sr}$ added, then mass fractionation corrections assuming normal ${ }^{86} \mathrm{Sr} /{ }^{88} \mathrm{Sr}$ result in

$$
\begin{gathered}
\left({ }^{87} \mathrm{Sr} /{ }^{86} \mathrm{Sr}\right)_{\mathrm{C}}=(1+\lambda / 2-\nu / 2)\left({ }^{87} \mathrm{Sr} /{ }^{86} \mathrm{Sr}\right)_{\mathrm{S}} \\
\left({ }^{84} \mathrm{Sr} /{ }^{88} \mathrm{Sr}\right)_{\mathrm{C}}=(1-2 \lambda+2 \nu)\left({ }^{84} \mathrm{Sr} /{ }^{88} \mathrm{Sr}\right)_{\mathrm{S}}
\end{gathered}
$$

where $\mathrm{C}$ denotes ratios corrected for mass fractionation and $\mathrm{S}$ denotes the true composition in the sample. If the Sr FUN anomalies reside only in ${ }^{84} \mathrm{Sr}$ (i.e., $\lambda=\mu=\nu=0$ ), then no artifacts are present in $\left({ }^{87} \mathrm{Sr} /{ }^{86} \mathrm{Sr}\right)_{C}$ due to the fractionation correction. If the FUN anomalies are due only to ${ }^{88} \mathrm{Sr}$, then $\left({ }^{87} \mathrm{Sr} /{ }^{86} \mathrm{Sr}\right)_{\mathrm{C}}$ will be offset from $\left({ }^{87} \mathrm{Sr} /{ }^{86} \mathrm{Sr}\right)_{\mathrm{S}}$ by $-\nu / 2$. For EK 1-4-1, the reported initial $\left({ }^{87} \mathrm{Sr} /{ }^{86} \mathrm{Sr}\right)_{\mathrm{C}}$ in Table 2 (footnote h) should be higher than in the sample by $1.6 \%$ and therefore the true ${ }^{87} \mathrm{Sr} /{ }^{86} \mathrm{Sr}$ in the sample(s) must be lower by $1.6 \%$ than BABI or ALL. If we now consider that the FUN effects are due to ${ }^{86} \mathrm{Sr}$, then $\left({ }^{87} \mathrm{Sr} /{ }^{86} \mathrm{Sr}\right)_{\mathrm{S}}$ would be lower than BABI or ALL by $\sim 0.8 \%$ and would correspond to "primitive" ${ }^{87} \mathrm{Sr} /{ }^{86} \mathrm{Sr}$ due to addition of ${ }^{86} \mathrm{Sr}$. The close agreement of $\left({ }^{8}{ }^{7} \mathrm{Sr} /{ }^{86} \mathrm{Sr}\right)_{\mathrm{C}}$ in EK 1-4-1 with values in the interval BABI-ALL is either fortuitous, or indicates that the $\mathrm{Sr}$ anomalies in EK 1-4-1 are not due to a ${ }^{88} \mathrm{Sr}$ deficit. The arguments presented demonstrate that the nuclear effects in $\mathrm{Sr}$ can result in computational artifacts in the ${ }^{87} \mathrm{Sr} /{ }^{86} \mathrm{Sr}$, which are considerably larger than the difference between BABI and ALL. However, we note that inclusion $D 7$, which defines the most primitive measured ${ }^{87} \mathrm{Sr} /{ }^{86} \mathrm{Sr}$, has normal ${ }^{84} \mathrm{Sr} /{ }^{88} \mathrm{Sr}$ composition. If the difference BABI-ALL were an artifact due to the presence of an excess in ${ }^{88} \mathrm{Sr}$ [Cameron, 1973], we should have measured $\delta 84=+0.6 \%$, which is not in agreement with the precise new analysis. We conclude that, although the discovery of nuclear anomalies in $\mathrm{Sr}$ may affect the use of ${ }^{87} \mathrm{Sr} /{ }^{86} \mathrm{Sr}$ as an early solar system chronometer, there is no direct evidence of large artifacts in ${ }^{87} \mathrm{Sr} /{ }^{86} \mathrm{Sr}$. We believe that, with care, ${ }^{87} \mathrm{Sr} /{ }^{86} \mathrm{Sr}$ measurements may still provide a useful chronometer. Future studies must certainly include high precision ${ }^{84} \mathrm{Sr}$ measurements on the unspiked samples.

Acknowledgement. We thank A. G. W. Cameron for his insightful and tempered review while the ball game is still open. This work was supported by NASA NGL 05-002-188 and NSF 76-83685.

\section{References}

Burbidge, E.M., G.R. Burbidge, W.A. Fowler, and F. Hoyle, Synthesis of the elements in stars, Rev. Mod. Phys., 29, 547-650, 1957.

Cameron, A.G.W., Are large time differences in meteorite formation real', Nature, 246, 30-32, 1973.

Chen, J.H., and G.R. Tilton, Isotopic lead investigations on the Allende carbonaceous chondrite, Geochim. Cosmochim Acta, 40, 635-644, 1976.

Clayton, R.N., L. Grossman, and T.K. Mayeda, A component of primitive nuclear composition in carbonaceous meteorites, Science, 182, 485-488, 1973.

Clayton, R.N., and T.K. Mayeda, Correlated $\mathrm{O}$ and $\mathrm{Mg}$ isotope anomalies in Allende inclusions: I. Oxygen, Geophys. Res. Letters, 4, 295-298, 1977.

Clayton, R.N., N. Onuma, L. Grossman, and T.K. Mayeda, Distribution of the pre-solar component in Allende and other carbonaceous chondrites, Earth Planet. Sci. Letters, 34, 209-224, 1977.

Gray, C.M., D.A. Papanastassiou, and G.J. Wasserburg, Primitive ${ }^{8} \mathrm{Sr} /{ }^{86} \mathrm{Sr}$ in the Allende carbonaceous chondrite, Trans. Amer Geophys. Union, 54, 17, 1973a.

The identification of early condensates from the solar nebula, Icarus, 20, 213-239, $1973 \mathrm{~b}$.

Lee, T., and D.A. Papanastassiou, $\mathrm{Mg}$ isotopic anomalies in the Allende meteorite and correlation with $\mathrm{O}$ and $\mathrm{Sr}$ effects, Geophys. Res. Letters, 1, 225-228, 1974.

Lee, T., D.A. Papanastassiou and G.J. Wasserburg, Demonstration of ${ }^{26} \mathrm{Mg}$ excess in Allende and evidence for ${ }^{26} \mathrm{Al}$, Geophys. Res. Letters, 3, 109-112, 1976.

${ }^{26} \mathrm{Al}$ in the early solar system: fossil or fuel?, $A p . J$ (Letters), 211, 107-110, 1977.

Ca isotopic anomalies in the Allende meteorite, Ap. $J$ (Letters), 220, 21-25, 1978.

Lugmair, G.W., K. Marti, and N.B. Scheinin, Incomplete mixing of products from r-, p-, and s-process nucleosynthesis: Sm-Nd systematics in Allende inclusion EK1-04-1, in Lunar and Planetary Science IX, Lunar and Planetary Institute, Houston, p. 672-674, 1978.

McCulloch, M.T., and G.J. Wasserburg, Ba and Nd isotopic anomalies in the Allende meteorite, $\bar{A} p$. $\bar{J}$. (Letters), 220, 15-19, 1978a.

More mysteries from the Allende meteorite: Sm, Geophys. Res. Letters, 5, 1978b (in press, this issue).

McCulloch, M.T., G.J. Wasserburg, and D.A. Papanastassiou, More mysteries from Pandora's Box, Abs., FICGCIG (Snowmass), 1978.

Papanastassiou, D.A., J.C. Huneke, T.M. Esat, and G.J. Wasserburg, Pandora's Box of the nuclides, in Lunar and Planetary Science IX, Lunar and Planetary Institute, Houston, p. 859-861, 1978.

Papanastassiou, D.A., and G.J. Wasserburg, Initial $\mathrm{Sr}$ isotopic abundances and the resolution of small time differences in the formation of planetary objects, Earth Planet. Sci. Letters, 5, 361-376, 1969.

Seeger, P.A., W.A. Fowler, and D.D. Clayton, Nucleosynthesis of heavy elements by neutron capture, Ap. J. Suppl., 97, 121-166, 1965.

Tatsumoto, M., D.M. Unruh, and G.A. Desborough, U-Th-Pb and Rb-Sr systematics of Allende and U-Th-Pb systematics of Orgueil, Geochim. Cosmochim. Acta, 40, 617-634, 1976.

Wasserburg, G.J., T. Lee, and D.A. Papanastassiou, Correlated $\mathrm{O}$ and $\mathrm{Mg}$ isotopic anomalies in Allende inclusions: II. Magnesium, Geophys. Res Letters, 4, 299-302, 1977.

Woosley, S.E., and W.M. Howard, The p-process in supernovae, Ap. $J$ Suppl. Series, 36, 285-304, 1978.

(Received May 8, 1978; accepted May 23, 1978.) 